\title{
Evidence for cardiac atrophic remodeling in cancer-induced cachexia in mice
}

\author{
MIN TIAN $^{1}$, MICHELLE L. ASP ${ }^{1}$, YOSHINORI NISHIJIMA $^{2}$ and MARTHA A. BELURY ${ }^{1}$ \\ ${ }^{1}$ Department of Human Nutrition, College of Education and Human Ecology, \\ ${ }^{2}$ College of Pharmacy, The Ohio State University, Columbus, OH, USA
}

Received March 11, 2011; Accepted April 26, 2011

DOI: 10.3892/ijo.2011.1150

\begin{abstract}
Cachexia is a common complication in cancer patients, which dramatically reduces quality of life and survival. In contrast to the well-studied feature of skeletal muscle loss, alterations in cardiac muscle are unclear. Recently, we reported that heart contractile function was significantly impaired in mice with colon-26 (C26) tumors, a widely used rodent model of cancer cachexia. In the present study, we investigated the potential underlying mechanisms for decreased heart function, specifically related to cardiac remodeling and atrophy. In cachectic mice bearing C26 tumors compared to mice without tumors, there was a gene expression pattern for cardiac remodeling, including increased BNP and c-fos, decreased PPAR $\alpha$ and its responsive gene CPT1 $\beta$, and a switch from 'adult' isoforms (MHC $\alpha$, GLUT4) to 'fetal' isoforms (MHC $\beta$ and GLUT1). Echocardiography identified a decreased cardiac wall thickness. RT-PCR and Western blotting revealed a decreased amount of cardiac myofibrillar proteins MHC and troponin I, induced expression of E-3 ligases (MuRF-1 and Atrogin-1) and increased protein ubiquitination, providing evidence for cardiac atrophy in mice with cancer cachexia. Regulatory signaling pathways mediating these changes may include p44/42 MAPK. Together, these data provide evidence that pathways leading to cardiac remodeling and atrophy occur in mice with C26 cachexia.
\end{abstract}

\section{Introduction}

Cachexia is a complex metabolic syndrome that occurs in $30-90 \%$ of cancer patients and is estimated to account for $22 \%$ of cancer deaths $(1,2)$. The prominent feature of cancer cachexia is the severe loss of skeletal muscle mass and strength, which contributes to weakness and fatigue and adversely affects patients' quality of life and tolerability of cancer therapies (3).

Correspondence to: Dr Martha A. Belury, Department of Human Nutrition, College of Education and Human Ecology, The Ohio State University, 1787 Neil Avenue, Columbus, OH, USA

E-mail: belury.1@osu.edu

Key words: MuRF-1, Atrogin-1, troponin I, myosin heavy chain
The decreased skeletal muscle mass in cancer cachexia is mainly attributed to the marked induction of ubiquitin-proteasome mediated proteolysis, where E3 ligases Atrogin-1 (also called MAFbx) and MuRF-1 are commonly elevated $(4,5)$.

In contrast to the well-defined mechanisms of skeletal muscle atrophy, alterations in cardiac muscle have received relatively little attention. It is unclear whether cancer cachexia causes heart failure, although a 1975 observational study reported that $7 \%$ of cancer deaths could be attributed to cardiovascular insufficiency (6). In earlier studies using tumor-bearing animals, cardiac performance measured $e x$ vivo was unaffected despite some evidence of abnormal cardiac muscle metabolism $(7,8)$. In a recent study from our group, we found that heart contractile function was impaired measured by echocardiography in mice with C26 tumorinduced cachexia, and this was accompanied with increased fibrosis, deranged myocardium structure, and altered gene expression of contractile proteins (9). Springer and colleagues (10) also reported deterioration of cardiac function in cachectic rats with $\mathrm{AH}-130$ hepatoma, with transient elevation of brain natriuretic peptide (BNP). BNP is a hormone secreted by cardiac myocytes and is generally highly expressed in the fetal, but not adult myocardium. Increased BNP is considered to be one of the events in cardiac remodeling indicating a cardiac pathological response (11). From these studies, there is now substantial evidence of heart function deterioration in cancer cachexia, but the underlying mechanism remains to be determined.

The purpose of the present study was to further characterize the $\mathrm{C} 26$ tumor-induced cachexia mouse model to elucidate the alterations in the cardiac muscle. We hypothesized that cardiac remodeling and atrophy occur in mice with cancer cachexia, and ubiqutin-proteasome mediated proteolysis may be a contributory factor.

\section{Materials and methods}

Experimental animals and design. Five-week-old, male CD2F1 mice (BALB/c x DBA/2; Charles River Laboratories, Wilmington, MA) were housed five per cage and fed the AIN-93G semipurified pellet diet (Research Diets, New Brunswick, NJ) containing $7 \%$ fat by weight. When mice weighed approximately 20 grams (day 0), they were randomly assigned to either the Tumor $(n=15)$ or No Tumor $(n=10)$ group, and were inoculated 


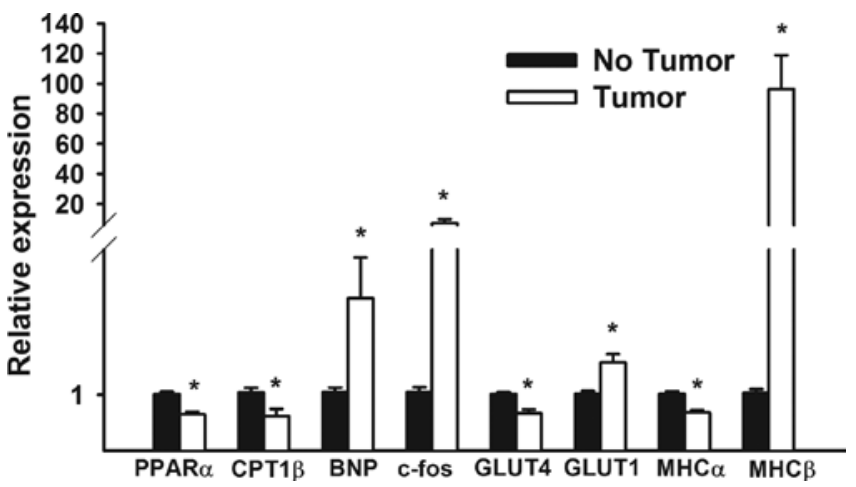

Figure 1. Gene expression of cardiac remodeling in mice in the No Tumor group $(n=10)$ compared to the Tumor group $(n=14)$. ${ }^{*} P<0.05$.

Table I. In vivo echocardiographic data.

\begin{tabular}{lcc}
\hline Parameters & No Tumor & Tumor \\
\hline IVSs (mm) & $1.21 \pm 0.04$ & $0.87 \pm 0.04^{\mathrm{b}}$ \\
LVPWs (mm) & $1.49 \pm 0.08$ & $1.05 \pm 0.03^{\mathrm{b}}$ \\
IVSd (mm) & $0.72 \pm 0.01$ & $0.61 \pm 0.01^{\mathrm{b}}$ \\
LVPWd (mm) & $0.89 \pm 0.08$ & $0.73 \pm 0.04$ \\
LVIDd (mm) & $3.4 \pm 0.1$ & $3.3 \pm 0.1$ \\
LVIDs (mm) & $1.8 \pm 0.1$ & $2.3 \pm 0.1^{\mathrm{b}}$ \\
LVEF (\%) & $85.2 \pm 1.6$ & $67.1 \pm 2.3^{\mathrm{b}}$ \\
Fractional shortening (\%) & $48.6 \pm 2.1$ & $32.3 \pm 1.7^{\mathrm{b}}$ \\
\hline
\end{tabular}

Values are means \pm SEM. IVSs, interventricular septum wall thickness at systole; IVSd, interventricular septum wall thickness at diastole; LVPWs, left ventricle posterior wall thickness at systole; LVPWd, left ventricle posterior wall thickness at diastole; LVIDd, left ventricle internal diameter at diastole; LVIDs, left ventricule internal diameter at systole; LVEF, left ventricular ejection fraction. ${ }^{\text {aThese values have }}$ been reported previously (9). ${ }^{\text {b }} \mathrm{P}<0.05$.

subcutaneously in the flank region with either $1 \times 10^{6}$ colon-26 adenocarcinoma cells or PBS as vehicle, respectively. On day 17 post-inoculation, when there was a $20 \%$ difference in body weight between the No Tumor and Tumor groups, mice were sacrificed by cervical dislocation. Hearts were harvested first and ventricles were processed for RT-PCR and Western blot analysis. All procedures were in accordance with institution guidelines and approved by the Institutional Animal Care and Use Committee of The Ohio State University.

Echocardiography. At day 14 after tumor/PBS inoculation when there was a $18 \%$ difference in body weight between the Tumor and No Tumor group, echocardiography on mice was performed using a GE Vivid7 ultrasound system (GE, Waukesha, WI) as previously described (9).

Western immunoblots. Hearts were rapidly excised and a portion of the ventricles was homogenized in lysis buffer (20 mM trizma base, $1 \%$ Triton X-100, $50 \mathrm{mM} \mathrm{NaCl}, 250 \mathrm{mM}$ sucrose, $50 \mathrm{mN} \mathrm{NaF}, 5 \mathrm{mM} \mathrm{Na}{ }_{4} \mathrm{P}_{2} \mathrm{O}_{7} . \mathrm{H}_{2} \mathrm{O}$ ) with Complete Mini Protease Inhibitor Cocktail Tablets (Roche Diagnostics,
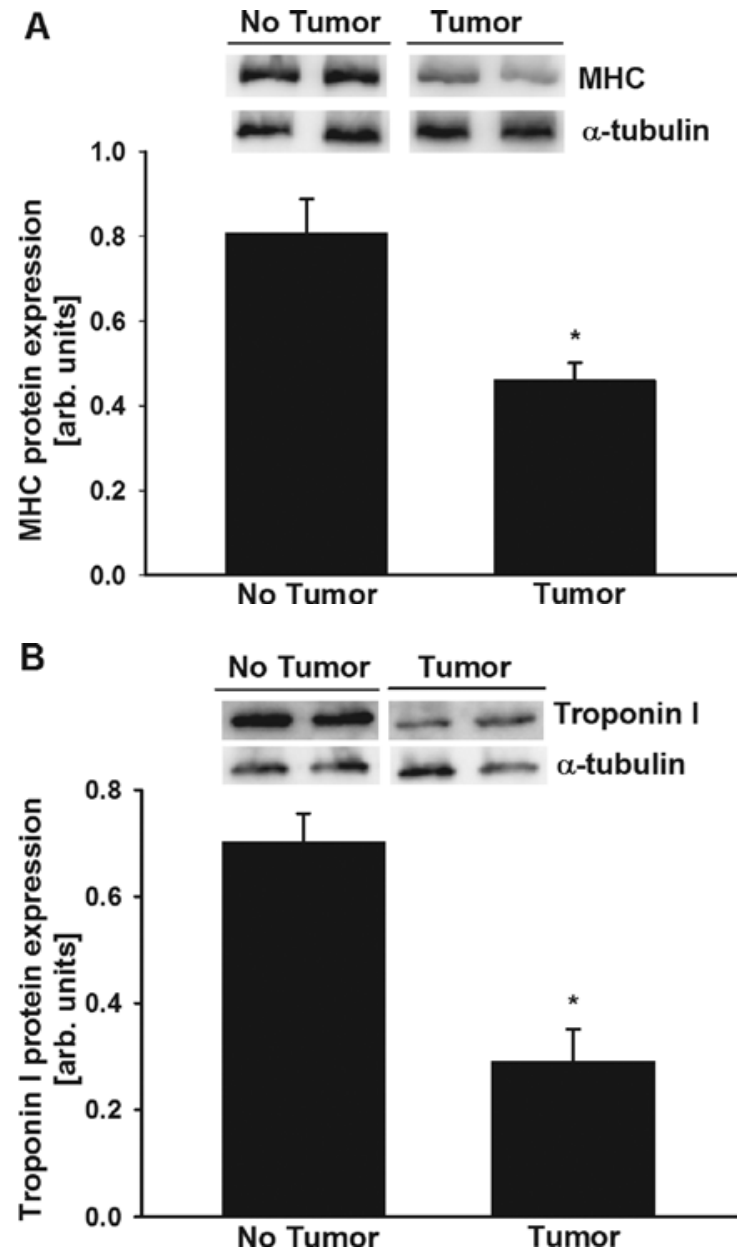

Figure 2. Detection and quantification of MHC (A) and Troponin I (B) protein expression in mice in the No Tumor group $(n=10)$ compared to the Tumor group $(n=14)$. $P<0.05$. Representative Western blots using cardiac MHC and Tropinin I antibodies are depicted, respectively. To control for equal loading of the lanes, the blot was re-probed with anti- $\alpha$-tubulin antibody.

Indianapolis, IN). Protein concentration was determined using the BCA Protein Assay kit (Pierce, Rockford, IL). Protein (60 $\mu \mathrm{g}$ per sample) was separated by SDS-PAGE, and transferred to nitrocellulose membranes. Ponceau S Solution (Sigma, St. Louis, MO) was used to examine bands for equal loading for SDS- PAGE and confirm successful transfer to the membrane. Membranes were probed for target proteins according to manufacturer's protocol and then detected with chemiluminescense (Super Signal, Pierce, Rockford, IL) using Kodak Image Station 2000 RT (Eastman Kodak, Rochester, NY). Polyclonal rabbit anti-phospho- and total-p44/42 MAPK and p38 MAPK, anti-troponin I, anti- $\alpha$-tubulin, and secondary antibody (HRP- linked anti-rabbit IgG) were purchased from Cell Signaling (Danvers, MA). Anti-MuRF1 was purchased from Novus Biologicals LLC (Littleton, CO). Polyclonal mouse anti-myosin heavy chain-cardiac and secondary antibodies (HRP-linked anti-mouse IgG) were from Abcam (Cambridge, MA).

RT-PCR analysis. RNA was isolated from the ventricles with TRIzol reagent (Invitrogen, Carlsbad, CA) and reverse transcribed with the High Capacity cDNA Archive kit (ABI, 
A

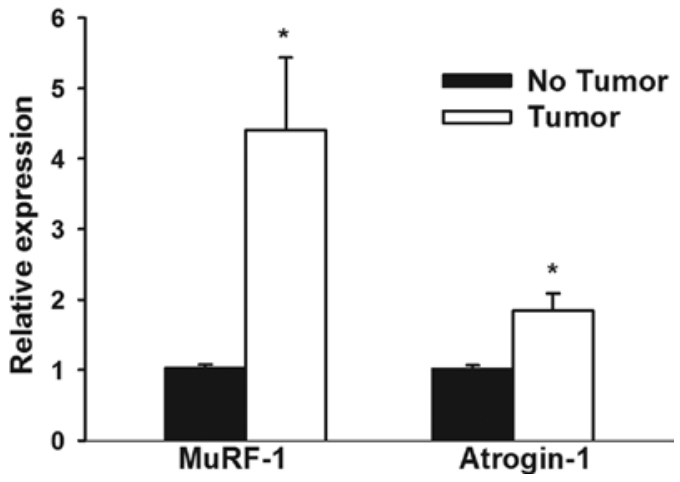

B

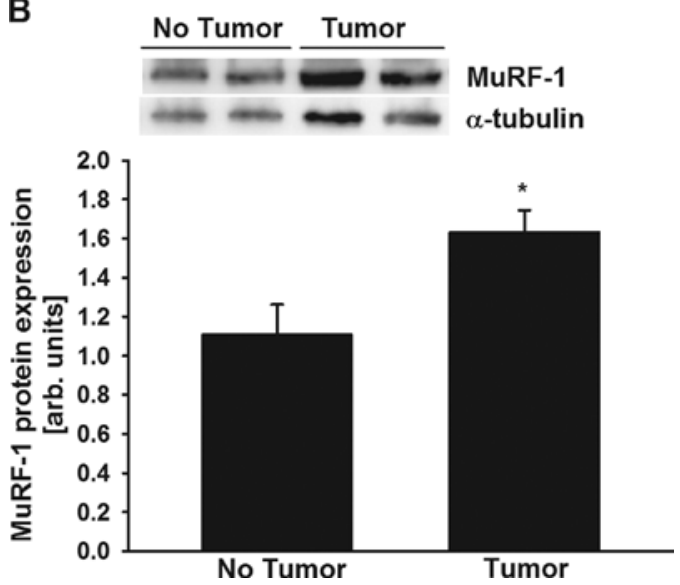

Figure 3. Analysis of MuRF-1 and Atrogin-1 mRNA expression by RT-PCR (A) as well as MuRF-1 protein expression by Western blot analysis (B) in mice in the No Tumor group $(\mathrm{n}=10)$ compared to the Tumor group $(\mathrm{n}=14)$. ${ }^{*} \mathrm{P}<0.05$. Representative Western blots using a MuRF-1 specific antibody are depicted. To control for equal loading of the lanes, the blot was re-probed with anti$\alpha$-tubulin antibody.

Foster City, CA) according to the manufacturer's protocol. RT-PCR analysis was performed with pre-designed primers from Applied Biosystems (TaqMan Gene Expression Assays). Target gene expression was normalized to the endogenous control 18S rRNA amplified in the same reaction and expressed as $2^{-\Delta \Delta C T}$ relative to the No Tumor group (12).

Statistical analysis. Data were analyzed using MINITAB 15 (State College, PA) and are presented as mean \pm standard error of mean (SEM). Differences between the Tumor and No Tumor groups were analyzed by unpaired, two-sample t-tests. Differences were considered significant at $\mathrm{P}<0.05$.

\section{Results}

Gene expression pattern associated with cardiac remodeling is present in mice with cancer cachexia. Impaired cardiac function is usually associated with a series of molecular alterations in the myocardium, so-called cardiac remodeling. Molecular alterations during cardiac remodeling include increased fibrosis, reduced expression of PPAR $\alpha$ and responsive genes (13), re-expression of proto-oncogenes, and activation of fetal gene expression $(11,14,15)$. Our previous study demonstrated increased interstitial fibrosis between cardiac myofibers, as well as a

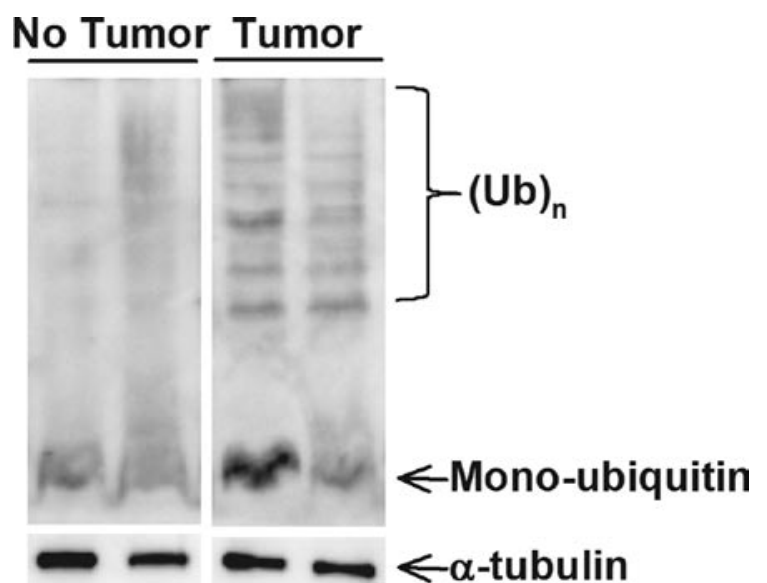

Figure 4. Detection of ubiquitinated proteins in the myocardium of mice in the Tumor group $(n=8)$ compared to the No Tumor group $(n=8)$. Representative Western blot analysis using an ubiquitin specific antibody is depicted. To control for equal loading of the lanes, the blot was re-probed with anti- $\alpha$-tubulin antibody.

switch from 'adult' isoform MHC $\alpha$ to 'fetal' isoform MHC $\beta$ in the falling hearts of mice with cancer cachexia (9). In this study, we found additional evidence of cardiac remodeling in cachectic mice bearing $\mathrm{C} 26$ tumors. The expression of PPAR $\alpha$ mRNA and its responsive gene CPT1 $\beta$ mRNA were significantly reduced, while the expression of BNP and proto-oncogene c-fos mRNA were significantly induced in hearts of tumorbearing mice. In addition to the myofibrillar protein MHC switching from adult to fetal isoform, there was a decreased GLUT4 (adult isoform) expression and an increased GLUT1 (fetal isoform) expression (Fig. 1).

Cardiac wall thickness is decreased in mice with cancer cachexia. With impaired heart contractile function revealed by significantly decreased fractional shortening (Table I), the M-mode imaging from transthoracic echocardiography identified a $28 \%$ decrease in interventricular septum (IVS) wall thickness and a $30 \%$ decrease in posterior wall thickness at systole, as well as a 15\% decrease in IVS wall thickness at diastole, suggesting cardiac wall atrophy in tumor-bearing mice (Table I).

Myocardium protein degradation is increased in mice with cancer cachexia. Corroborating the evidence of cardiac atrophy identified by echocardiography, we found significantly decreased proteins levels in the major cardiac myofibrillar proteins, a 43\% reduction in MHC (Fig. 2A) and a 58\% reduction in troponin I (Fig. 2B) in tumor-bearing mice compared to mice without tumors. To determine whether the ubiquitin-proteasome system is involved in the loss of myofibrillar proteins, RT-PCR and additional Western blots were performed. Significantly higher mRNA and protein levels of MuRF-1 as well as a higher gene expression of Atrogin-1 were evident in hearts of tumor-bearing mice (Fig. 3A and B), consistent with a higher level of protein ubiquitination (Fig. 4). These data suggest that the ubiquitinproteasome system may be contributing to the cardiac protein loss in tumor-bearing mice. 

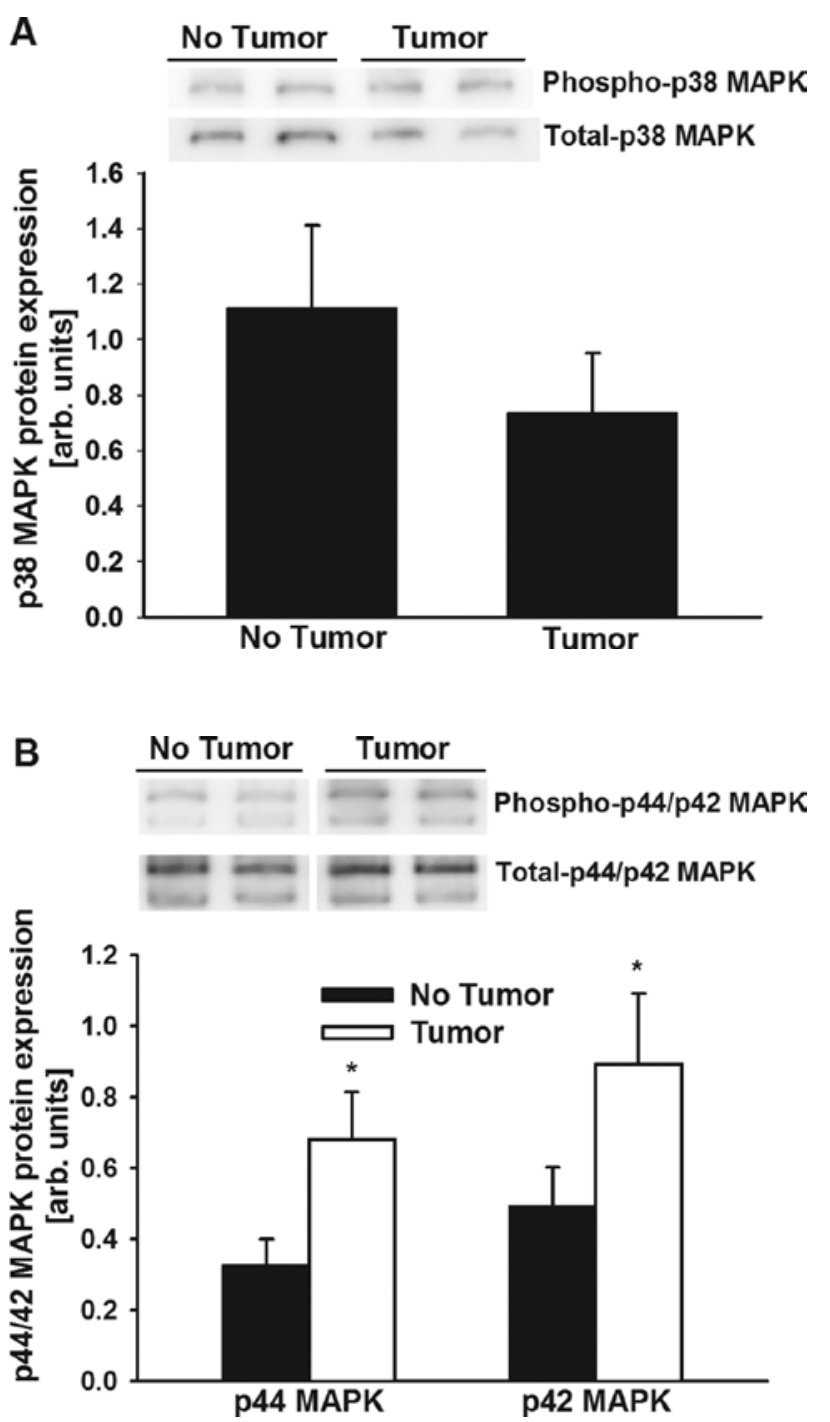

Figure 5. Detection and quantification of the activation (phosphorylated form relative to total form) of p38 MAPK (A) and p44/42 MAPK (B) in the myocardium of mice in the Tumor group $(n=8)$ compared to the No Tumor group $(\mathrm{n}=8) .{ }^{*} \mathrm{P}<0.05$.

In cachexia, E-3 ligases (Atrogin-1 and MuRF-1) are mainly induced by pro-inflammatory cytokines (16), which are found to be elevated in our study. In the C26 mouse model of cancer cachexia, IL- 6 is the dominant pro-inflammatory cytokine (17). We have found more than 100 -fold induction in circulating IL-6 in tumor-bearing mice (Belury MA, unpublished data), as well as increased local inflammation in the heart (9). Different signaling pathways mediated through pro-inflammatory cytokines have been reported in cardiac atrophy, and MAPK activation has been believed to be conserved, including p38 MAPK and p44/42 MAPK $(13,16)$. Therefore, we performed Western blots to detect activation of p38 MAPK and p44/42 MAPK. The results showed a significantly elevated p44/42 MAPK activation (phosphorylated form relative to total form) in the myocardium of tumor-bearing mice compared to mice without tumors (Fig. 5B), without a difference detected in p38 MAPK activation (Fig. 5A).



Figure 6. Proposed working model for the regulation of cardiac muscle atrophy in mice with colon-26 tumor-induced cachexia.

\section{Discussion}

Our previous study uncovered an underappreciated deterioration of heart contractile function in mice with C26 tumor-induced cachexia (9). The present study investigates the underlying mechanism of the decreased heart function. We found induction of a gene expression pattern indicative of cardiac pathological development in mice with cancer cachexia. In addition, echocardiography demonstrated decreased cardiac wall thickness, which is in accordance with the loss of major myofibrillar proteins MHC and troponin I. The induced expression of E-ligases (Atrogin-1 and MuRF-1), increased protein level of MuRF-1, together with increased protein ubiquitination suggest that ubiquitin-proteasome mediated proteolysis may in part contribute to the cardiac muscle atrophy in mice with cancer cachexia.

Cardiac remodeling usually occurs after injury to the heart and is indicative of declined heart function. The remodeling process is characterized by altered sarcomeric gene expression, including activation of proto-oncogenes (c-fos, c-jun, c-myc, hsp70) (15), and decreased expression of PPAR $\alpha$ and PPAR $\alpha$ regulated genes (13). Cardiac muscle derives the majority $(\sim 70 \%)$ of its energy from lipid oxidation (18), and PPAR $\alpha$ is the major regulator of lipid metabolism in mammalian hearts. It induces expression of CPT1, which is the key enzyme in the outer membrane of mitochondria for fatty acid uptake and the rate-limiting step for fatty acid $\beta$-oxidation. Inhibition of PPAR $\alpha$ regulation is associated with impaired oxidative capacity (e.g. mitochondria biogenesis) and energy substrate utilization switch from lipid to glucose, with a consequence of compromised heart function (19). In patients with dilated cardiomyopathy, there is a down-regulation of genes involved in fatty acid oxidation, as well as the switch from fatty acid to glucose utilization $(20,21)$. We found a reduction in PPAR $\alpha$ and CPT $1 \beta$ expression in hearts of tumor-bearing mice compared to mice without tumors, suggesting a reduced capacity of fatty acid $\beta$-oxidation, which needs further confirmation by activity assay.

Another key feature of the altered gene expression pattern is the switch from 'adult' to a 'fetal' gene expression profile. BNP is a hormone secreted by fetal cardiac myocytes, and we found a significant BNP induction in the heart of C26 tumorbearing mice. Decreased MHC $\alpha$ and increased MHC $\beta$ is well-documented in heart failure, and this shift adversely 
impacts cardiac contractile capacity $(15,22-24)$. In addition to MHC isoforms, we also found a switch from GLUT4 to GLUT1. Similar findings have been reported in both animals and patients with heart failure $(14,25)$. GLUT4 is mainly found in adult muscle and adipose tissue and is responsible for glucose uptake in response to insulin, while GLUT1 is widely distributed in fetal tissues, and is responsible for low-level basal glucose uptake. The GLUT isoform switch may be an adaptive mechanism to compensate for the hypoglycemia that occurs in later stages of cachexia in this model (26).

Re-activation of fetal gene expression occurs in both cardiac atrophic and hypertrophic remodeling (27-29). In our studies, several lines of evidence support the possibility of cardiac atrophy in C26-tumor bearing mice. We found a $21 \%$ reduced heart mass in cachectic mice bearing C26 tumors compared to control mice (9), which is consistent with findings of others that heart sizes were decreased by $20-29 \%$ in C26 tumorbearing mice and inhibin-deficient mice with gonadal cancers (30). Moreover, the echocardiography clearly demonstrated decreased cardiac wall thickness, suggestive of cardiac atrophy. In support of this notion, Western blotting revealed a reduced amount of MHC and troponin I. MHC accounts for the majority of myofibrillar proteins and hydrolyzes ATP for muscle force generation, while troponin I is the major regulator of the muscle contractile apparatus (22). The degradation of contractile proteins is negatively associated with maximal force generation (31). There has been evidence that MuRF-1 localizes to the $\mathrm{M}$ line in the center of the thick filament and specifically degrades troponin I in hearts (32) and MHC in skeletal muscle $(33,34)$, while Atrogin-1 (MAFbx) degrades Myo D (35). We found increased MuRF-1 at both mRNA and protein levels, together with increased Atrogin-1 gene expression. However, Atrogin-1 protein level could not be determined due to a lack of a specific antibody. Additionally, increased protein ubiquitination was detected. These data indicate that the cardiac atrophy might occur in part through the activation of ubiquitinproteasome system in the tumor-bearing mice.

Chronic induction of pro-inflammatory cytokines, such as TNF- $\alpha$ and IL- 6 are associated with cardiac remodeling in both human falling hearts and in experimental animal models (36-38). These cytokines are potent activators of E-3 ligase (MuRF-1 and Atrogin-1) expression in cardiac muscle (16). Conraads and colleagues demonstrated that TNF- $\alpha$ plays an important role in the process of left ventricular remodeling following acute myocardial infarction. In the early hypertrophy phase of cardiac remodeling, TNF- $\alpha$ activated Akt and downregulated the E3-ligases, therefore increased the level of contractile proteins (troponin I in particular) and cardiac hypertrophy in patients (39). But in a rat model of chronic heart failure, which is a later phase of cardiac remodeling with left ventricle dilation and wall thinning, TNF- $\alpha$ induced the expression of Atrogin-1 through activation of p38 MAPK, and induced MuRF-1 through p42/44 MAPK in cardiac muscle (16). In our study using the C26 mouse model, IL-6 is the major cytokine and found to be elevated in both heart and the circulation $(9,17)$. To investigate whether MAPK mediated signaling is involved, we detected the activation (phosphorylation) of p38 MAPK and p44/42 MAPK, and only p44/42 MAPK was found to be activated in hearts of tumor-bearing mice compared to mice without tumors. To elucidate whether p44/42 MAPK is required and sufficient to regulate cardiac proteolysis, further mechanistic work should be addressed in future studies, e.g. examining proteolysis in cardiomyocytes under specific inhibition of the p44/42 MAPK activity.

In summary, cardiac atrophic remodeling occurs in the cachectic mice bearing C26 tumors. Although partly speculative, we would like to propose the hypothetical working model outlined in Fig. 6. Future in vitro experiments will confirm the role of pro-inflammatory cytokines in regulating cardiac atrophy as well as the involvement of p44/42 MAPK pathway.

\section{Acknowledgements}

This study was supported by the Kennedy Professorship at The Ohio State University and a grant from the Ohio Agricultural Research and Development Center.

\section{References}

1. Band PR, Bennett JM, Bertino JR, Cohen MH, Douglass HO Jr, Engstrom PF, Ezdinli EZ, Horton J, Johnson GJ, Moertel CG, Oken MM, Perlia C, Rosenbaum C, Silverstein MN, Skeel RT, Sponzo RW and Tormey DC: Prognostic effect of weight loss prior to chemotherapy in cancer patients. Eastern Cooperative Oncology Group. Am J Med 69: 491-497, 1980.

2. Warren S: The immediate causes of death in cancer. Am J Med Sci 184: 610-615, 1932.

3. Inui A: Cancer anorexia-cachexia syndrome: current issues in research and management. CA Cancer J Clin 52: 72-91, 2002.

4. Bodine SC, Latres E, Baumhueter S, Lai VKM, Nunez L, Clarke BA, Poueymirou WT, Panaro FJ, Na E, Dharmarajan K, Pan ZQ, Valenzuela DM, De Chiara TM, Stitt TN, Yancopoulos GD and Glass DJ: Identification of ubiquitin ligases required for skeletal muscle atrophy. Science 294: 1704-1708, 2001.

5. Gomes MD, Lecker SH, Jagoe R, Navon A and Goldberg AL: Atrogin-1 a muscle specific F-box protein highly expressed during muscle atrophy. Proc Natl Acad Sci USA 98: 14440-14445, 2001.

6. Ambrus JL, Ambrus CM, Mink IB and Pickren JW: Causes of death in cancer patients. J Med 6: 61-64, 1975.

7. Sjostrom M, Wretling ML, Karlberg I, Edén E and Lundholm K: Ultrastructural changes and enzyme activities for energy production in hearts concomitant with tumor-associated malnutrition J Surg Res 42: 304-313, 1987.

8. Drott C, Ekman L, Holm S, Waldenström A and Lundholm K: Effects of tumor-load and malnutrition on myocardial function in the isolated working rat heart. J Mol Cell Cardiol 18: 1165-1176, 1986.

9. Tian M, Nishijima Y, Asp ML, Stout MB, Reiser PJ and Belury MA: Cardiac alterations in cancer-induced cachexia in mice. Int J Oncol 37: 347-353, 2010.

10. Springer J, Tschirner A, Palus S, Grzesiak A, Kaschina E, Argiles J, von Haehling S and Anker SD: Severe progressive heart failure in experimental cancer cachexia only transiently elevates BNP. J Cachexia Sarcopenia Muscle 1:111 (Abst 151), 2010.

11. Cheng L, Ding G, Qin Q, Huang Y, Lewis W, He N, Evans RM, Schneider MD, Brako FA, Xiao Y, Chen YE and Yang Q: Cardiomyocyte-restricted peroxisome proliferator-activated receptor-delta deletion perturbs myocardial fatty acid oxidation and leads to cardiomyopathy. Nat Med 10: 1245-1250, 2004.

12. Livak KJ and Schmittgen TD: Analysis of relative gene expression data using real-time quantitative PCR and the 2(-Delta Delta C(T)) method. Methods 25: 402-408, 2001.

13. Razeghi P, Wang ME, Youker KA, Golfman L, Stepkowski S and Taegtmeyer H: Lack of NF-kappaB1 (p105/p50) attenuates unloading-induced downregulation of PPARalpha and PPARalpharegulated gene expression in rodent heart. Cardiovasc Res 74: 133-139, 2007.

14. Wellner M, Dechend R, Park JK, Shagdarsuren E, Al-Saadi N, Kirsch T, Gratze P, Schneider W, Meiners S, Fiebeler A, Haller H, Luft FC and Muller DN: Cardiac gene expression profile in rats with terminal heart failure and cachexia. Physiol Genomics 20: 256-267, 2005 
15. Gidh-Jain M, Huang B, Jain P, Gick G and El-Sherif N: Alterations in cardiac gene expression during ventricular remodeling following experimental myocardial infarction. J Mol Cell Cardiol 30: 627-637, 1998

16. Adams V, Linke A, Wisloff U, Döring C, Erbs S, Kränkel N, Witt CC, Labeit S, Müller-Werdan U, Schuler G and Hambrecht R: Myocardial expression of MuRF-1 and MAFbx after induction of chronic heart failure: effect on myocardial contractility. Cardiovasc Res 73: 120-129, 2007.

17. Strassmann G, Fong M, Kenney JS and Jacob CO: Evidence for the involvement of interleukin 6 in experimental cancer cachexia. J Clin Invest 89: 1681-1684, 1992.

18. Lopaschuk GD, Ussher JR, Folmes CD, Jaswal JS and Stanley WC: Myocardial fatty acid metabolism in health and disease. Physiol Rev 90: 207-258, 2010.

19. Ingwall JS: Energy metabolism in heart failure and remodeling. Cardiovas Res 81: 412-419, 2009.

20. Feinendegen LE, Henrich MM, Kuikka JT, Thompson KH, Vester EG and Strauer B: Myocardial lipid turnover in dilated cardiomyopathy: a dual in vivo tracer approach. J Nucl Cardiol 2: 42-52, 1995.

21. Sack MN, Rader TA, Park S, Bastin J, McCune SA and Kelly DP: Fatty acid oxidation enzyme gene expression is downregulated in the failing heart. Circulation 94: 2837-2842, 1996.

22. Nakao K, Minobe W, Roden R, Bristow MR and Leinwand LA: Myosin heavy chain gene expression in human heart failure. J Clin Invest 100: 2362-2370, 1997.

23. Tardiff JC, Hewett TE, Factor SM, Vikstrom KL, Robbins JA and Leinwand LA: Expression of the beta(slow)-isoform of MHC in the adult mouse heart causes dominant-negative functional effects. Am J Physiol Heart Circ Physiol 278: H412-H419, 2000.

24. Nadal-Ginard B and Mahdavi V: Molecular basis of cardiac performance. Plasticity of the myocardium generated through protein isoform switches. J Clin Invest 84: 1693-1700, 1989.

25. Razeghi P, Young ME, Alcorn JL, Moravec CS, Frazier OH and Taegtmeyer H: Metabolic gene expression in fetal and failing human heart. Circulation 104: 2923-2931, 2001.

26. Tanaka Y, Eda H, Tanaka T, Udagawa T, Ishikawa T, Horii I, Ishitsuka H, Kataoka T and Taguchi T: Experimental cancer cachexia induced by transplantable colon 26 adenocarcinoma in mice. Cancer Res 50: 2290-2295,1990.

27. Sharma S, Ying J, Razeghi P, Stepkowski S and Taegtmeyer H: Atrophic remodeling of the transplanted rat heart. Cardiology 105: 128-136, 2006

28. Razeghi P, Sharma S, Ying J, Li YP, Stepkowski S, Reid MB and Taegtmeyer H: Atrophic remodeling of the heart in vivo simultaneously activates pathways of protein synthesis and degradation. Circulation 108: 2536-2541, 2003
29. Depre C, Shipley GL, Chen W, Han Q, Doenst T, Moore ML, Stepkowski S, Davies PJ and Taegtmeyer H: Unloaded heart in vivo replicates fetal gene expression of cardiac hypertrophy. Nat Med 4: 1269-1275, 1998.

30. Zhou X, Wang JL, Lu J, Song Y, Kwak KS, Jiao Q, Rosenfeld R, Chen Q, Boone T, Simonet WS, Lacey DL, Goldberg AL and Han HQ: Reversal of cancer cachexia and muscle wasting by ActRIIB antagonism leads to prolonged survival. Cell 142: 531-543, 2010.

31. Van der Velden J, Merkus D, Klarenbeek BR, James AT, Boontje NM, Dekkers DH, Stienen GJ, Lamers JM and Duncker DJ: Alterations in myofilament function contribute to left ventricular dysfunction in pigs early after myocardial infarction. Circ Res 95: E85-E95, 2004.

32. Kekar V, McDonough H, Arya R, Li H, Rockman HA and Patterson C: Muscle-specific RING finger 1 is a bona fide ubiquitin ligase that degrades cardiac troponin I. Proc Natl Acad Sci USA 101: 18135-18140, 2004.

33. Clarke BA, Drujan D, Willis MS, Murphy LO, Corpina RA, Burova E, Rakhilin SV, Stitt TN, Patterson C, Latres E and Glass DJ: The E3 ligase MuRF1 degrades myosin heavy chain protein in dexamethasone-treated skeletal muscle. Cell Metab 6: 376-385, 2007.

34. Acharrya S, Ladner KJ, Nelsen LL, Damrauer J, Reiser PK, Swoap S and Guttridge DC: Cancer cachexia is regulated by selective targeting of skeletal muscle gene products. J Clin Invest 114: 370-378, 2004.

35. Tintignac LA, Lagirand J, Batonnet S, Sirri V, Leibovitch MP and Leibovitch SA: Degradation of MyoD mediated by the SCF (MADbx) ubiquitin ligase. J Biol Chem 280: 2847-2856, 2005.

36. Torre-Amione G, Kapadia S, Lee J, Durand JB, Bies RD, Young JB and Mann DL: Tumor necrosis factor-alpha and tumor necrosis factor receptors in the failing human heart Circulation 93: 704-711, 1996

37. Kanda $\mathrm{T}$ and Takahashi T: Interleukin- 6 and cardiovascular diseases. Jpn Heart J 45: 183-193, 2004.

38. Kapadia S, Dibbs Z, Kurrelmeyer K, Kalra D, Seta Y, Wang F, Bozkurt B, Oral H, Sivasubramanian N and Mann DL: The role of cytokines in the failing human heart. Cardiol Clin 16: 645-656, 1998.

39. Conraads VM, Vrints CJ, Rodrigus IE, Hoymans VY, Van Craenenbroeck EM, Bosmans J, Claeys MJ, Van Herck P, Linke A, Schuler G and Adams V: Depressed expression of MuRF1 and MAFbx in areas remote of recent myocardial infarction: a mechanism contributing to myocardial remodeling? Basic Res Cardiol 105: 219-226, 2010. 